\title{
Greece's Stock Market Integration with Southeast Europe
}

\author{
Khaled Guesmi \\ IPAG Business School \& EconomiX (UMR CNRS 7235)University of Paris West-La Défense, France \\ Zied Ftiti \\ IPAG Business School, Paris, France \\ Ilyes Abid \\ EM-Normandie, Le Havre, France
}

\begin{abstract}
This paper analyzes the time-varying integration of the Greek stock market from a regional perspective by using a conditional version of the international capital asset pricing model (ICAPM) allowing for dynamic changes in the degree of market integration, regional market currency risk, and local market risk. We show that the prices of risk are extremely sensitive to major international economic and political events such as the different monetary and financial crises in Asian and Latin American countries in 1997, 1998, and 2001. In addition, we show that the level of market openness and development of the stock market satisfactorily explain the time-varying degree of Greek stock market integration.
\end{abstract}

\section{JEL Classifications: G12, F31, C32}

Key words: International Capital Asset Pricing Model(ICAPM), Market Integration, Exchange Rate Risk

\footnotetext{
* Corresponding Author: Khaled Guesmi; Department of Finance (IPAG Lab), IPAG Business School, 184 Boulevard St Germain 75006 Paris, France; French; Tel: +33 01550440, Fax: +33 0145444046, E-mail: Khaled.guesmi@ipag.fr.

Co-Author: Zied Ftiti; Department of Finance (IPAG Lab), IPAG Business School \& Department of Quantitative methods, High Institute of Management, Office C-e1, ISG, 41 rue de la liberté bouchoucha, le Bardo, 2000, France; French and Tunisian; Tel: +33 6481772 14, Fax: +33 0145444046, E-mail: Zied.Ftiti@isg.rnu.tn;

Ilyes Abid; Departement of Finance (Métis Lab), EM-Normandie, 30 rue de Richelieu 76087 Le Havre Cedex, France; Tunisian; Tel: +33 695876651, Fax: + 33 235421116, E-mail: iabid@em-normandie.fr.
} 


\section{Introduction}

The increasing integration in Western European financial markets, which have reduced a priori the potential gains from international portfolio diversification, has lead to the development of emerging financial markets which are considered to offer new opportunities. It has become traditional to restructure research opportunities according to the logic of large geographic poles as Latin America, Eastern Europe, Middle East, and Asia. This geographical diversification does not really take into account the heterogeneity of each of these clusters. ${ }^{1}$ Geographical classification is meant to arbitrate major divisions among them and should therefore lead to financial integration and the realization of the law of single international price. However, such a design requires an adjustment of the foreign exchange market. In addition, when we look at the international diversification of portfolios, we can a priori doubt about the realization of the law of one price because that exchange rate regime implements a more or less strict regulation by local authorities. Moreover, the process of regionalization is generally based on the analysis of the trade flows of goods in the literature (Freudenberg et al. 1998) and the flow of intra-regional direct investment (Petri, 2006). These methods of analysis, however, remain inadequate since they do not account for interactions between local factors and international ones.

The study of regionalization must be attached to the financial valuation models of financial assets that can both identify common risk factors and measuring unit compensations associated with these factors. In such context, Stulz (1981) explains that a completely integrated financial market is a situation where investors earn the same risk adjusted expected return on similar financial markets. Rezai (2007) proves that a stock market is considered to be better integrated if there are stronger domestic returns facing the shocks of the international market. This definition underlines not only the openness of stock markets but also measures the extent to which shocks are transferred across financial markets. The transfer of a shock requires both the removal of barriers and the capital flows across markets in order to take advantage of market opportunities. It is considered that, in case of a more fully integrated stock financial market, the country's economy and the subject market will not be separated from any outside influence. Choudhry et al. (2007) mentioned that financial market development improves the

\footnotetext{
The heterogeneity originate from financial integration factors, such as level of financial market development, economic policy followed, trade openness, etc.
} 
degree of integration among these markets. Moreover, financial integration among markets has gained considerable attention from both finance specialists and policy makers.

To summarize, we refer to the conclusions of Adler and Dumas (1983), Carrieri et al. (2007), and Tai (2007). We consider, in addition to the systematic risks associated with regional and local markets, changes in exchange rates which are relevant sources of risk in pricing emerging market assets according to previous studies.

Our study contributes to the existing literature by examining the dynamic regional integration of the Greek stock market in the Southeast European region (Czech Republic, Greece, Poland, Romania, Bulgaria, and Croatia) together with its determinants in the context of the partially integrated ICAPM whose theoretical foundations have recently developed in Arouri et al. (2012). The ICAPM allows for a smooth transition between different integration regimes. Specifically, expected returns may move from a perfectly segmented regime to a perfectly integrated one or vice versa, depending on a certain number of national and regional factors that are likely to drive the process of regional financial integration. Although the proposed model was developed in the spirit of that presented by Bekaert and Harvey (1995), it allows for the dynamic conditional correlations between stock returns by using the multivariate Generalized Auto Regressive Conditional Heteroskedasticity-Dynamic Conditional Correlation(GARCH-DCC) model of Engle (2002). It also examines the relevance of the dynamic measure of financial integration over the conditional correlations, very frequently used in literatures when referring to the level of integration.

Our empirical results show that the degree of trade openness and local stock market development significantly affects changes in regional financial integration. They also point to the validity of the ICAPM and indicate that exchange rate risk is priced regionally. As in previous studies, we find that stock market integration evolves through time and its changing patterns differ across markets.

The remainder of the article is organized as follows. Section II presents the empirical approach used to identify the determinants of financial integration and examine the dynamics of regional financial integration for our sample markets. Section III describes the data and their statistical properties. Section IV reports the obtained results. Section $\mathrm{V}$ provides the concluding remarks. 


\section{The Model}

Our empirical asset pricing model is based on the Bekaert and Harvey (1995) model and inspired by the theoretical models of partial integration of Black (1974), Stulz (1981), Cooper and Kaplanis (2000), Hardouvelis (2006), De Santis et al. (2003), Guesmi and Nguyen (2011), and Arouri et al. (2012). These authors confirm the partial integration hypothesis and time-varying world market integration for most individual markets. Exchange rate risk is also found to be priced in the context of both developed and emerging markets.

In our study, we adopt a partially integrated conditional ICAPM with three sources of systematic risks that globally reflect fluctuations in regional stock market, national stock market, and exchange rate. Generally, the conditional mean of excess return can be written as:

$$
\begin{aligned}
& E\left(R_{\text {Greece }, t} \mid \pi_{t-1}\right)=\Theta_{t-1}\left[\eta_{\text {reg }, t-1} \operatorname{Cov}\left(R_{\text {Greece }, t}, R_{\text {reg }, t} \mid \pi_{t-1}\right)+\eta_{k, t-1} \operatorname{Cov}\left(R_{\text {Greece }, t}, R_{k, t} \mid \pi_{t-1}\right)\right] \\
& +\left(1-\Theta_{t-1}\right) \eta_{t-1} \operatorname{Var}\left(R_{\text {Greece }, t} \mid \pi_{t-1}\right)
\end{aligned}
$$

Where $R_{\text {Greece, },}, R_{\text {reg, } t}$, and $R_{k, t}$ represent, respectively, expected excess returns on the local market portfolio, excess return on the South Eastern stock market index, and excess currency return conditionally on a set of information $\left(\pi_{t-1}\right)$ that is available to investors up to time $t-1 . \eta_{r e g, t-1}, \eta_{t-1}$, and $\eta_{k, t-1}$ are the expected prices of a unit of risk, related to the regional market, the local market, and the currency risk, respectively. $\Theta_{t-1}$ refers to a conditional measure for the financial integration degree of the Greek market with the regional market. Let $G_{t-1}, D_{t-1}$, and $F_{t-1}$ denote, respectively, the vector of regional information variables, the vector of local information variables, and the vector of integration variables available at time $t-1$. The expected prices of risk and the dynamics of market integration can then be modeled as:

$$
\begin{aligned}
& \eta_{r e g, t-1}=\operatorname{Exp}\left(\delta_{r e g}^{\prime} G_{t-1}\right) \\
& \eta_{t-1}=\operatorname{Exp}\left(\gamma^{\prime} D_{t-1}\right) \\
& \eta_{k, t-1}=\left(\delta_{k}^{\prime} G_{t-1}\right) \\
& \Theta_{t-1}=\operatorname{Exp}\left(-\left|\alpha^{\prime} F_{t-1}\right|\right)
\end{aligned}
$$


A market is fully integrated into the regional market when $\Theta_{t-1}=1$. In this case, the expected return on Greek market depends on its covariance with the regional stock market and on the exchange rate returns. Thus, the model in equation (1) becomes the two-factor regional CAPM allowing for deviations from purchasing power parity (PPP). If $\Theta_{t-1}=0$, the Greek market is completely segmented from the regional market. The expected return is, therefore, determined uniquely with respect to the local market risk, and the model in equation (1) is reduced to the domestic CAPM. When $\Theta_{t-1}$ is in the range 0 and 1 , the Greek market is in partial integration with the regional market and asset-pricing relationship is based on a combination of regional, local, and exchange rate risk factors.

Under the hypothesis of rational expectations, the econometric specification in Equation (1) is characterized by the system of equations as follows:

$$
\begin{aligned}
& \tilde{r}_{\text {Greece }, t}^{c}=\Theta_{t-1}\left(\eta_{\text {reg, },-1} h_{\text {Greece, }, \text { reg }, t}+\eta_{k, t-1} h_{\text {Greece }, k, t}\right)+\left(1-\Theta_{t-1}\right) \eta_{t-1} h_{\text {Greece, } t}+\varepsilon_{\text {Greece }, t} \\
& \tilde{r}_{r e g, t}^{c}=\eta_{r e g, t-1} h_{r e g, t}+\eta_{k, t-1} h_{r e g, k, t}+\varepsilon_{r e g, t} \\
& \tilde{r}_{k, t}^{c}=\eta_{r e g, t-1} h_{r e g, k, t}+\eta_{k, t-1} h_{k, t}+\varepsilon_{k, t} \\
& \varepsilon_{t}=\left(\varepsilon_{\text {Greece }, t}, \varepsilon_{\text {reg, }, t}, \varepsilon_{k, t} \mid \psi_{t-1}\right) \sim N\left(0, H_{t}\right) \\
& H_{t}=D_{t} L_{t} D_{t}^{\prime} \\
& L_{t}=\left(\operatorname{diag}\left(Q_{t}\right)\right)^{-1 / 2} Q_{t}\left(\operatorname{diag}\left(Q_{t}\right)\right)^{-1 / 2} \\
& D_{t}=\operatorname{diag}\left(\sqrt{h_{\text {Greece }, t}}, \sqrt{h_{\text {reg }, t}}, \sqrt{h_{k, t}}\right) \\
& \Theta_{t-1}=\operatorname{Exp}\left(-\left|\alpha_{0}+\alpha_{1}^{*} F_{t-1}\right|\right)
\end{aligned}
$$

Where $\widetilde{r}_{r e g, t}^{c}, \widetilde{r}_{k, t}^{c}$, and $\tilde{r}_{\text {Greece,t }}^{c}$ refer, respectively, to the vector of excess returns on the regional market, excess returns of the exchange rate, and excess returns of the local market. These returns are expressed in the currency of the reference country in order to compare results across markets. The parameters $h_{\text {Greece, reg, } t}, h_{\text {Greece, }, t,}, h_{\text {reg, } k, t}$ , $h_{\text {Greece, },}, h_{\text {reg,t }}$, and $h_{k, t}$ are, respectively, the conditional covariance between Greek market return and regional market return, the conditional covariance between Greek market return and exchange rate $k$ 's return, the conditional covariance between regional market return and exchange rate $k$ 's return, the conditional variance of Greek market return, the conditional variance of regional market return, and the conditional variance 
of rate $k^{\prime}$ s return, all being issued from the $(3 \times 3)$ variance-covariance matrix $H_{t} \cdot h_{k, t}$ the conditional variance of the exchange rate index with $k=$ (Czech Republic, Poland, Croatia and Romania). The exchange rate index is measured by the geometric weighted average of all individual countries' exchange rates against the US dollar. The weights are the share of each country in its foreign trade with the rest of the world. We model $H_{t}$ by using a multivariate GARCH-DCC model as described in Engle (2002). $L_{t}$ is the $(3 \times 3)$ symmetric matrix of dynamic conditional correlations. $D_{t}$ is a diagonal matrix of conditional standard deviations for each of the return series obtained from estimating a univariate GARCH process. $Q_{t}$ is a $(3 \times 3)$ variance-covariance matrix of standardized residuals $\left(u_{t}=\varepsilon_{t} / \sqrt{h_{t}}\right)$.

The parameter $\Theta_{t-1}$ is our measure of the time-varying degree of market integration. Our model extends the literature in that we simultaneously take into account currency risks, volatility, and correlation dynamics to accommodate the so-called leverage effect.

In line with previous work, we estimate the system (3) as follows. ${ }^{2}$ In the first stage, we use the Quasi-Maximum Likelihood Estimation (QMLE) method to estimate the system of equations corresponding to the excess return on regional market and excess return on the exchange rate. This step gives us the risk premiums associated with regional market and exchange rate risk as well as the conditional variance of the regional market and its exchange rate. In the second stage, we estimate the complete system with three equations to identify the regional financial integration.

\section{Data}

We use monthly excess stock returns of the one-month Eurodollar interest rate which is considered a risk-free rate. Monthly stock returns are calculated from stock market indices with dividends reinvested according to the formula $R_{i t}=\operatorname{In}\left(P_{t} / P_{t-1}\right)$. Regional return index corresponds to the geometric mean of stock returns weighted by the market capitalization of each member country. All market index data are obtained from Thomson DataStream International.

Real effective exchange rate (REER) indices are employed to represent the exchange rate risk. In the case of emerging markets, the inflation rate has a greater volatility than

\footnotetext{
Errunza et al. (1992), Cooper and Kaplanis (2000) and Bhattacharya and Daouk (2002) also adopt this procedure to estimate their partially segmented ICAPM.
} 
the exchange rate. The REER indices are measured by the geometric weighted average of all individual countries' exchange rates against the US dollar. The weights are the share of each country in its foreign trade with the rest of the world. These indices are calculated monthly by using exchange rate and trade data obtained from the DataStream International database, the Federal Reserve Bank of St. Louis database, and the IMF's International Financial Statistics database. Their returns are determined as the logarithm difference between two consecutive index values. By construction, the REER index also allows for cross-country comparisons of changes in trade competitiveness.

To condition the time-variations in the prices of risks related to the regional stock market, we use a constant $(E C O N)$, dividend yield in excess of the 30-day regional market risk-free rate $(E D I V)$, regional market portfolio excess return of risk-free rate $(E R E T U R N)$, and interest rate spread $(E S P R)$ measured by the yield difference between the 10-year US Treasury notes and the 3-month US Treasury bills. All these monthly data are extracted from the Morgan Stanley Capital Index (MSCI) and DataStream International databases.

The local instrumental variables used in order to infer changes in the local risk are: i) the dividend yield of the local market portfolio $(G D I V)$, ii) the return on the local stock market index in excess of the one-month Eurodollar interest rate (GRETURN), and iii) the monthly change in the trade-weighted average regional inflation rate (GINF). These instrumental variables are obtained from DataStream International and Morgan Stanley Capital International(MSCI) databases.

Since there is a numerical convergence problem on the estimation stage when we have more than two unknown parameters, only two information variables are used to capture the evolution of market integration. Indeed, we choose the level of market openness (LMOP) measured by the ratio of imports plus exports to GDP and the development level of the stock market $(D L S M)$ as measured by the ratio of market capitalization to GDP. The choice of those variables is based on the Bayesian Information Criterion (BIC) and gives better statistical results.

Accordingly, the time-varying degree of market integration is modeled as:

$$
\Theta_{t-1}=\operatorname{Exp}\left(-\left|\alpha_{0}+\alpha_{1} \operatorname{LMOP}_{t-1}+\alpha_{2} D L S M_{t-1}\right|\right)
$$

Our study period runs from January 1996 through December 2007. It excludes episodes of the recent international financial crisis that could generate biased estimates. 


\section{Empirical Results}

For our asset-pricing model with partial integration, fluctuations in the regional stock market constitute a source of systematic risk. Contemporary international finance theory suggests that this risk is significant and priced: the higher the risk, the higher the reward. Figure 1 shows the evolution of the regional market's price of risk over the sample period and its smoothed series (or trend) obtained through the Hodrick-Prescott filter. ${ }^{3}$ We see that the price of regional market risk exhibits significant movements and varies from $0.21 \%(06 / 1998)$ to $0.53 \%$ (07/2001). From Figure 1, we observe two peaks in 1997 1998 and 2000 2002. By referring to economic events, these peaks coincide with the Asian crisis in 1997 1998 and with the It bubble burst in 2000 2002.

The disastrous collapse of the dot-coms that shook the U.S. economy started in May 2000. More than 200 dot-com companies failed in 2000 (see Hirakubo and Friedman, 2002) and more than 700 dot-coms between 2000 and 2001 (Pather et al., 2003). The dot-com bubble burst because the boom was based on the false premise that new technology would eliminate the need for brick-and-mortar stores as this new business model would supplant the old one, thereby converting the "Old Economy," which is based on the production of physical goods into a "New Economy," which is based on heavy use of information and technology (Rauch, 2001). In early 2000 the stock market witnessed a bubble ready to burst. This burst led to the rapid decline in the value of Internet-related stocks. In the weeks and days that followed the burst, the stock market bounced up and down randomly.

\footnotetext{
3 Hodrickand and Prescott (1997).
} 
Figure 1. Time-varying price of regional market risk

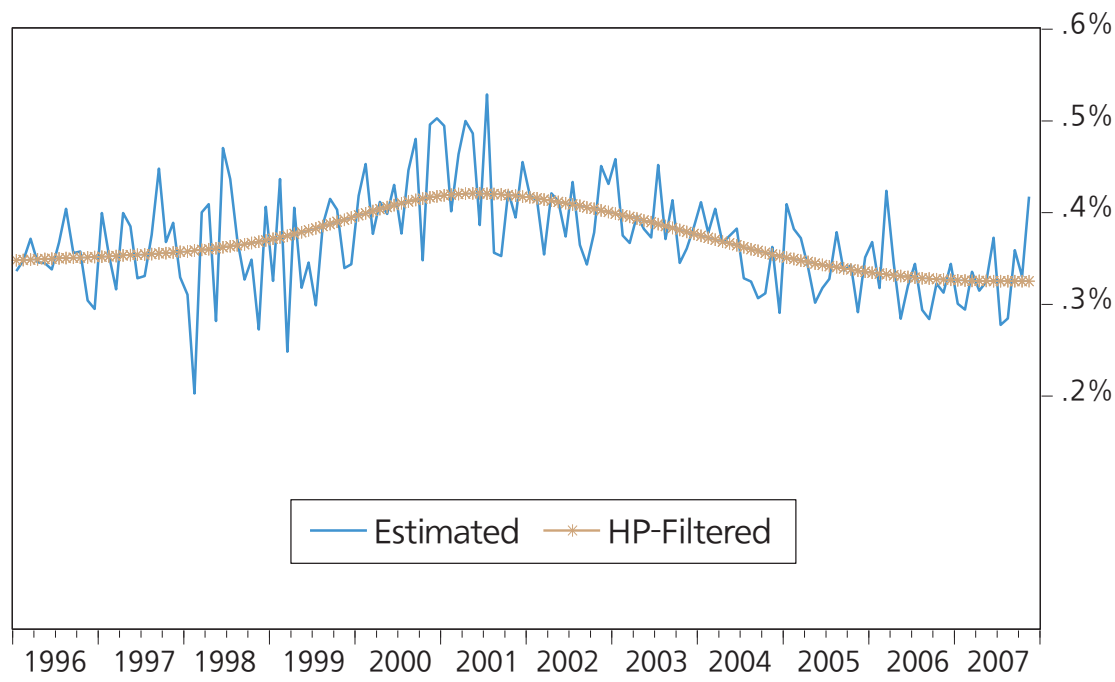

Figure 2. Time-varying price of exchange rate risk

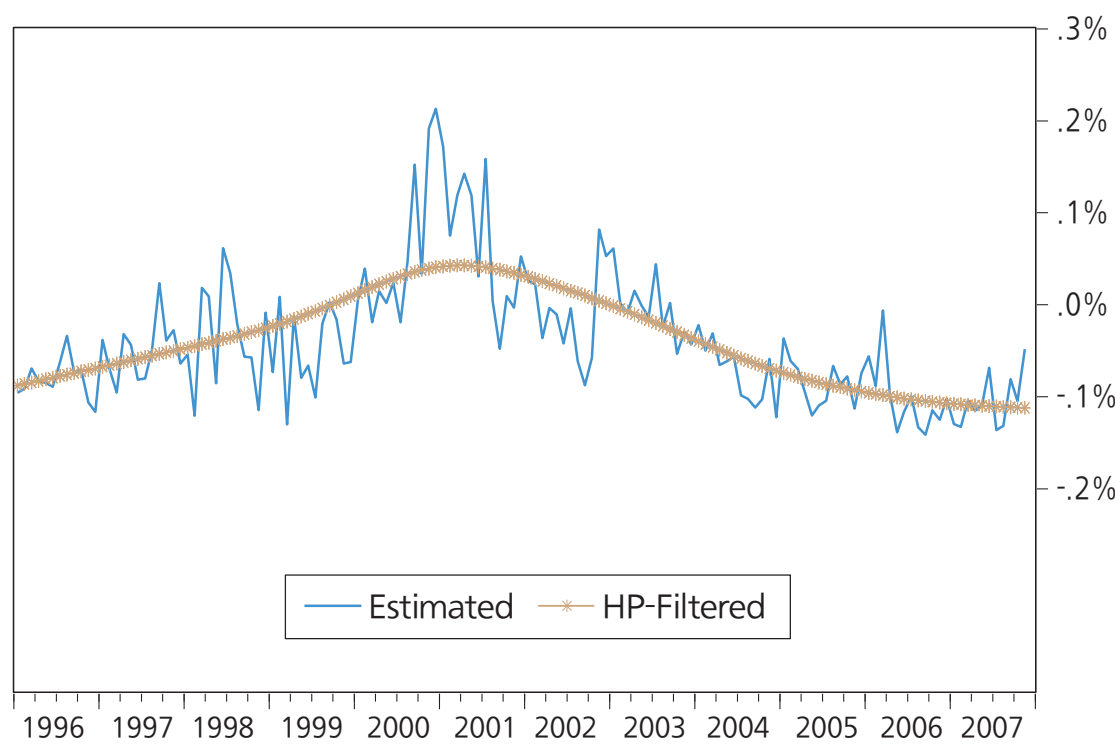

Figure 2 shows the dynamics of the exchange rate risk. For any market, the exchange rate risk is extremely sensitive to major international economic and political events such as the different monetary and financial crises in Asian and Latin American countries that occurred in 1997, 1998, and 2001. We can also note that the variations and the magnitudes of the risk have decreased after 2003. This fall is explained by a 
decline in market operators' risk aversion.

The filtered series reported in Figure 2 shows that the price of currency risk declined from year 2001 due to the opening of accession negotiations with the European Union and the improvement of trade balance were the cause of increased credibility combined with an influx of short-term capital. The highest values are recorded in 2000 and 2001 after the IT bubble burst and the terrorist attacks against the United States. However, the currency price of risk registers negative values over the entire period studied and knows booms in times of crisis.

The exchange rate risk is mainly determined by the dividend yield (EDIV) and stock returns $(E R E T U R N)$ of the regional markets. It is positively associated with dividend yield, but negatively associated with stock returns. Under a high return of the local markets, the raise of the activity trading in stock exchanges may potentially lead to a higher volatility in foreign exchange markets resulting to increased foreign investments.

We investigate the economic significance of the risk factors through two hypothesis tests. Our null hypotheses are respectively as follows: i) the prices of risk are zero and ii) the prices of risk are constant. The results from Wald tests, reported in Table 1, indicate the rejection of these null hypotheses at the $1 \%$ level. These findings effectively confirm those of previous studies, including for example Adler and Dumas (1983), Carrieri et al. (2007) Hardouvelis et al. (2006), and Guesmi and Nguyen (2011). 
Table 1. Determinants of the price for Exchange rate risk and Regional market risk

\begin{tabular}{|c|c|c|c|}
\hline$E C O N$ & $E D I V(\times 10)$ & ERETURN & $E S P R$ \\
\hline \multicolumn{4}{|l|}{ Panel A: Price of exchange rate risk } \\
\hline $0.367^{* *}$ & $0.007^{* * *}$ & $-0.004^{* *}$ & -0.008 \\
\hline$(0.168)$ & $(0.000)$ & $(0.001)$ & $(0.009)$ \\
\hline \multicolumn{4}{|l|}{ Panel B: Price of regional market risk } \\
\hline-0.032 & $0.006^{* * *}$ & $0.010^{* * *}$ & -0.001 \\
\hline$(0.031)$ & $(0.000)$ & $(0.000)$ & $(0.001)$ \\
\hline
\end{tabular}

Panel C: Specification tests for the prices for the regional market risk and exchange rate risk

\begin{tabular}{lll}
\hline Null hypotheses & $\chi^{2}$ & $p$-value \\
\hline Is the price of regional market risk null? $H_{0}: \eta_{\text {reg }}=0$ & $2.967^{*}$ & 0.085 \\
\hline Is the price of regional market risk constant? $H_{0}: \eta_{\text {reg }}=1$ & $1.829^{*}$ & 0.076 \\
\hline Is the price of exchange rate risk in Greece zero? $H_{0}: \eta_{k}=0$ & $56.987^{* * *}$ & 0.000 \\
\hline Is the price of exchange rate risk in Greece constant? $H_{0}: \eta_{k}=1$ & $75.971^{* * *}$ & 0.000 \\
\hline \hline
\end{tabular}

(Note) This table shows the determinants of exchange rate and regional market risk prices. ECON, EDIV, ERETURN, and ESPR represent the constant term, dividend yield, regional market returns, and interest rate spread. The numbers in parentheses are the associated standard deviations. $\chi^{2}$ is the empirical statistics of the Wald test examining the null hypotheses of nullity and constant coefficients. ${ }^{*}{ }^{* *}$, and ${ }^{* * *}$ indicate significance at the $10 \%, 5 \%$, and $1 \%$ rate, respectively.

The result in Table 2 shows that the prices of local market risk vary over time. Wald test confirms this result through the rejection of the null hypotheses that local risk prices are constant.

Table 2. Specification test of prices for Local market risk

\begin{tabular}{lll}
\hline Null Hypotheses & $\chi^{2}$ & $p$-value \\
\hline Is the price of local risk in Greece null? $H_{0}: \eta=0$ & $44.312^{* * *}$ & 0.000 \\
\hline Is the price of local risk in Greece constant? $H_{0}: \eta=1$ & $851.97^{* * *}$ & 0.000 \\
\hline
\end{tabular}

(Note) $\chi^{2}$ is the empirical statistics of the Wald tests examining the null hypotheses of nullity and constant coefficients. ${ }^{* *}$, and ${ }^{* * *}$ indicate rejection of the null hypotheses at the $5 \%$ and $1 \%$ rate, respectively.

Table 3 presents the results of the residual analysis. We examine their normality, autocorrelation, and conditional heteroscedasticity. First, we find that normality 
condition is rejected. Afterwards, the Ljung-Box test cannot reject the hypothesis of negative autocorrelation. At the end, we apply the Engle test (1982) to check for conditional heteroscedasticity; its result, however, rejects the ARCH effects. These results reveal the suitability and usefulness of the multivariate GARCH modeling approach.

Table 3. Analysis of residuals

\begin{tabular}{llllll}
\hline & Skewness & Kurtosis & J.B & Q(12) & ARCH(6) \\
\hline Greece & 0.599 & 2.865 & 8.613 & 14.640 & 0.062 \\
\hline
\end{tabular}

(Note) J.B, Q(12), and ARCH(6) are the empirical statistics of the Jarque-Bera test for normality, the LjungBox test for serial correlation of order 12, and the Engle (1982) test for conditional heteroscedasticity. ${ }^{* * *}$ indicates that the null hypothesis of normality, negative autocorrelation, and negative ARCH effect is rejected at the $1 \%$ level.

Table 4 reports the obtained results as well as the basic integration measure statistics estimated. Overall, the results confirm the identification of the integration's driving factors. These results show that their dynamics is significantly explained by the selected variables.

Table 4. Dynamics of regional integration

\begin{tabular}{llcc}
\hline $\begin{array}{l}\text { Panel A: Determinants of market } \\
\text { integration }\end{array}$ & Constant & $\begin{array}{c}\text { LMOP } \\
\text { (level of Market Openness) }\end{array}$ & $\begin{array}{c}\text { DLSM } \\
\left(\frac{\text { Market Capitalization }}{\text { GDP }}\right)\end{array}$ \\
\hline \multirow{2}{*}{ Greece } & $0.218^{* * *}$ & $0.055^{* * *}$ & $-0.138^{* * *}$ \\
& $(0.005)$ & $(0.008)$ & $(0.004)$ \\
\hline Panel B: Levels of market integration & $\Theta$ mean & $\Theta \max$ & $\Theta \min$ \\
\hline Greece & $0.699^{* * *}$ & 0.988 & 0.337 \\
\hline
\end{tabular}

(Note) This table shows the estimation results of the system (3) using the degree of trade openness and the level of stock market development as determinants of financial integration. The numbers in parentheses are standard deviations. ${ }^{* * *}$ indicates significance at the $1 \%$ rate.

Greece experienced decreases in the degree of integration (Figure 3), which reached levels below $40 \%$ over certain sub-periods. This is explained by the increase in the 
Greek deficits since the 1980s, which has a negative effect on the Greek financial system. Hibou (1997) explains that the introduction of VAT, which is designed to stop tax evasion and has an adverse effect due to the increase of tax intensity and the deterioration of the financial system. Moreover, contrary to expectations, tax rate reductions during the 1990s also failed to increase government revenues. This underachievement can be explained, on the one hand, by the failure of the tax audit system and the significant increase in imports from other Eurozone countries that are now not subject to national border controls. On the other hand, the pressure of debt repayments coupled with a sharp growth of the Greek public sector in recent years limited, to some extent, the resources available to uplift Greek productivity.

Figure 3. Time-varying market integration

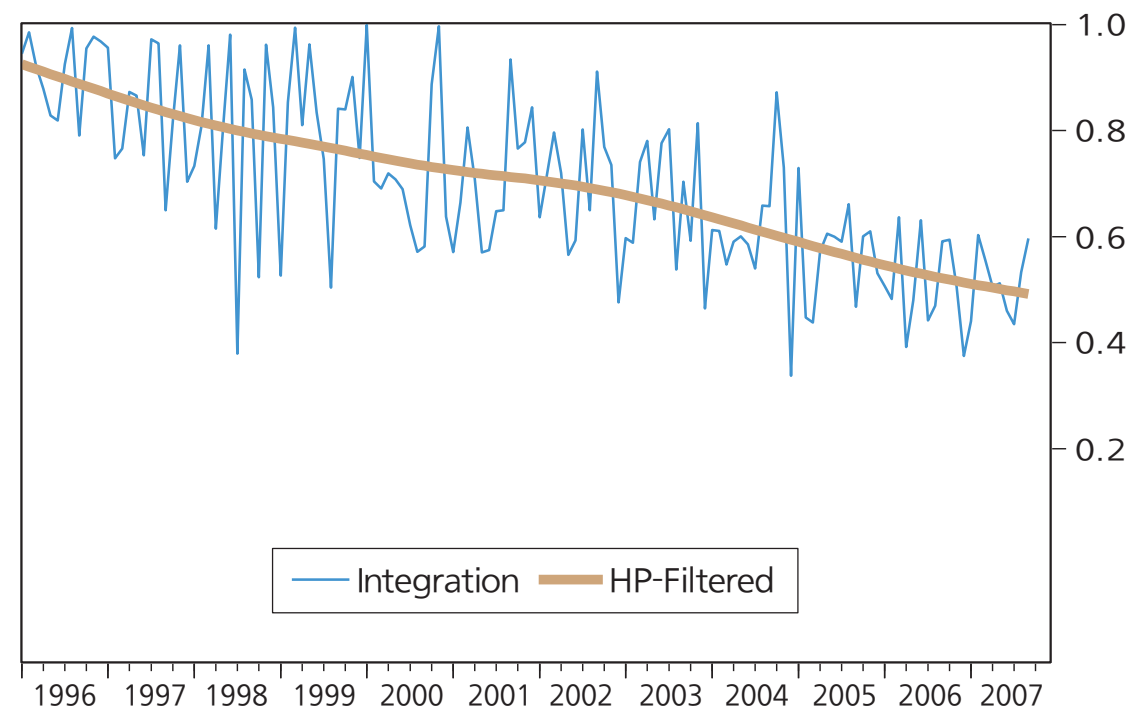

\section{Conclusion}

We developed a conditional ICAPM in the presence of exchange rate risk to study the dynamics of financial integration. Our empirical analysis was conducted on the basis of a nonlinear framework, which relies on the multivariate DCC-GARCH model. By allowing the prices of risk and the level of market integration to vary through time, we 
showed that Greece experienced decreases in the degree of integration, which reached levels below $40 \%$ over certain sub-periods.

Received 18 January 2013, Revised 10 June 2013, Accepted 18 June 2013

\section{References}

Adler, M., Dumas, B. (1983) International portfolio selection and corporation finance: A synthesis, Journal of Finance 38, pp. 925-984.

Arouri, M., Nguyen, D.K., Pukthuanthong, K. (2012) An international CAPM for partially integrated markets: Theory and empirical evidence, Journal of Banking and Finance, 36, pp. 2473-2493.

Bhattacharya, U., Daouk, H. (2002) The world price of insider trading, Journal of Finance, 57, pp. 75-108.

Bekaert, G., Harvey, C.R. (1995) Time-varying world market integration, Journal of Finance, 50, pp. 403-444.

Black, F. (1974) International capital market equilibrium with investment barriers,. Journal of Financial Economics, 1, pp. 337-352.

Carrieri, F., Errunza, V., Hogan, K., (2007) Characterizing world market integration through time, Journal of Financial and Quantitative Analysis, 42, pp. 915-940.

Choudhry, T., Lin, L., Peng, K. (2007) Common stochastic trends among Far East stock prices: Effects of the Asian financial crisis, International Review of Financial Analysis, 16, pp. 242-261.

Cooper, I. A., and Kaplanis E. (2000) Partially segmented international capital markets and international capital budgeting, Journal of International Money and Finance, 19, pp. 309-329.

Engle, R. (1982) Autoregressive conditional heteroskedasticity with estimates of the variance of U.K Inflation, Econometrica, 50, pp. 987-1008.

Engle, R., (2002) Dynamic conditional correlation: A simple class of multivariate GARCH models, Journal of Business and Economic Statistics, 20, pp. 339-350.

Errunza, V., Losq E., and Padmanabhan P. (1992) Tests of integration, mild segmentation and segmentation hypotheses, Journal of Banking and Finance, 16, pp. 949-972.

Freudenberg, M., Fontagne, L., Peridy, N., (1998) Commerce international et structures de marché : une vérification empirique, Économie et Prévision, 135, pp. 147-167.

Guesmi, K., Nguyen, D.K., (2011) How strong is the global integration of emerging market regions? An empirical assessment, Economic Modelling, 28, pp. 2517-2527.

Hardouvelis, G.A., Malliaropulos, D., Priestley, R. (2006) EMU and European stock market integration, Journal of Business, 79, pp. 365-373.

Hibou, B. (1997), La Grèce dans l'Europe: le révélateur budgétaire, Cahiers d'Etude sur la Méditerranée Orientale et le monde Turko-Iranien, 23, pp. 12-18.

Hirakubo, N., Friedman, H. H. (2002). Dot-bombs: Lessons from the dot-com debacle. Journal of Internet 
Commerce, 1(2), 89-102.

Hodrick, R., Prescott, E., (1997) Post war US business cycles: A descriptive empirical investigation, Journal of Money, Creditand Banking, 29(1), pp. 1-16.

Pather, S., Remenyi, D., Erwin, G. (2004). E-commerce success: the quest for IS effectiveness measurement: a conceptual framework for the e- commerce environment. South African Computer Journal, (32):34-43.

Petri, P.A., (2006) Is East Asia becoming more interdependent? Journal of Asian Economics 17, pp. 381-394.

Rezai, S. (2007) Breaking Out: The Dynamics of Immigrant Owned Businesses, Journal of Social Sciences, 3 , pp. 94-105.

Stulz, R. M. (1981) A model of international asset pricing, Journal of Financial Economics, 9, pp. 383-406.

Tai, C-S. (2007) Market integration and contagion: Evidence from Asian emerging stock and foreign exchange markets, Emerging Markets Review, 8, pp. 264-283. 